\title{
0 emprego da análise de imagem na determinação da distribuição de tamanho de partículas da areia presente no esgoto sanitário
}

\section{The use of image analysis to determine particle size distribution of grit carried by sewage}

\author{
Gustavo Silva do Prado \\ Egenheiro da Concremat Engenharia e Tecnologia S/A. Doutor em Engenharia Hidráulica e Sanitária pela Universidade de São Paulo (USP) \\ José Roberto Campos \\ Professor Titular do Departamento de Hidráulica e Saneamento da Escola de Engenharia de São Carlos da USP
}

\section{Resumo}

É consensual, no meio técnico, que unidades de desarenação devem reter partículas discretas de elevada velocidade relativa de sedimentação (por exemplo: areia, silte, cinzas, semente de frutas etc); e que desarenadores capazes de remover grãos de areia de tamanho maior ou igual a 0,2 mm removem a maior parte dos materiais que ocasionam problemas operacionais em estações de tratamento de esgoto (ETE). Entretanto, não existe concordância acerca da forma de se determinar a concentração ou a distribuição granulométrica de tais materiais no esgoto sanitário. O presente artigo apresenta um método para determinar a distribuição granulométrica da areia presente no esgoto sanitário, o qual se baseia no emprego de técnicas de análise de imagens digitais. A aplicação do método proposto demonstrou que, em média, 84\% da massa de areia carreada pelo esgoto sanitário afluente da ETE Jardim das Flores (Rio Claro, SP) era composta por partículas maiores ou iguais a 0,2 mm.

Palavras-chave: análise de imagem; distribuição de tamanho de partículas; desarenadores; esgoto sanitário; Estação de Tratamento de Esgoto Jardim das Flores.

\begin{abstract}
There is a consensus among technicians that degritters ought to remove discrete particles which present elevated settling velocities (e.g. sand, silt, ashes, fruit seeds etc.) and that units which are able to retain particles larger than or equal to $0.2 \mathrm{~mm}$ remove most of the material which causes operational problems to wastewater treatment plants (WWTP). Nevertheless, there is no agreement on how to determine grit concentration in wastewater and particle size distribution of this material. This paper presents a method to determine particle size distribution of grit carried by sewage based on the use of digital image analysis techniques. The use of the proposed method demonstrated that, on average, $84 \%$ of grit mass carried by the WWTP Jardim das Flores (Rio Claro, SP, Brazil) influent was made up of particles larger than or equal to $0.2 \mathrm{~mm}$.
\end{abstract}

Keywords: image analysis; particle size distribution; degritters; sewage; Wastewater Treatment Plant Jardim das Flores.

\section{Introdução}

Entre os diversos grupos de unidades que compõem estações de tratamento de esgoto (ETE), o tratamento preliminar, por ser considerado o menos "nobre", é certamente o que desperta menor interesse na comunidade científica. No entanto, de acordo com Wilson (1985), menosprezar o tratamento preliminar pode custar muito caro, pois somente os desarenadores (caixas de areia) podem responder por até um terço do custo operacional de uma ETE. O mesmo autor acrescenta que as despesas associadas à operação e manutenção de equipamentos de bombeamento, transporte e manuseio de lodo que contenha abrasivos são, no mínimo, cinco vezes maiores do que o estimado caso tais materiais não estivessem presentes.

Outros fatos que corroboram o desinteresse acerca do tratamento preliminar são: a carência de publicações acerca do tema e a inexistência de métodos padronizados para determinar a eficiência, nem 
mesmo, de desarenadores, cuja aplicação em plantas de depuração de águas residuárias remonta ao século 19 (GEIRGER, 1942). É consensual no meio técnico que unidades de desarenação devem reter partículas discretas de elevada velocidade relativa de sedimentação, como: areia, silte, borra de café, cinzas, sementes de frutas, fragmentos de ossos e cascas de ovos etc. Todavia, não existe concordância acerca de como quantificar a presença de tais materiais no esgoto sanitário.

Camp (1942) assevera não ser necessário quantificar todos os materias passíveis de remoção em desarenadores, porquanto a experiência demonstra que um desarenador capaz de remover grãos de areia de tamanho maior ou igual a 0,2 mm (200 $\mu \mathrm{m})$ removerá a maior parte do material que ocasiona problemas operacionais nas ETE. A aceitação tácita desses dizeres ao longo dos anos convencionou a quantidade de areia como o 'parâmetro' de controle das unidades de desarenação e 0,2 mm (200 $\mu \mathrm{m})$ como o tamanho dos menores grãos de areia que devem ser removidos em desarenadores.

Apesar de o "parâmetro" de controle para as unidades de desarenação estar definido e ser mundialmente aceito há várias décadas, não existem técnicas analíticas padronizadas para medi-lo. Gardner e Deamer (1996) alertam sobre as sérias consequências decorrentes da ausência de métodos padronizados para medição da quantidade (massa ou concentração) e da distribuição granulométrica da areia presente no esgoto sanitário, afluente e efluente de unidades de desarenação. Segundo os autores, esta carência metodológica dificulta negociações entre empresas que projetam e fornecem desarenadores e seus clientes (municipalidades, altarquias municipais, companhias de saneamento, empresas privadas etc), pois nem os fornecedores podem comprovar a eficiência de suas unidades, nem seus clientes podem verificar se as unidades fornecidas atendem às especificações de projeto.

Recentemente, em outra publicação, o tema foi trazido para discussão no círculo técnico (PRADO; CAMPOS, 2008). Neste artigo, os autores apresentam um método para determinar a quantidade (concentração) de areia presente no esgoto sanitário, que é original e viável para a grande maioria dos laboratórios de análise de ETE e de centros de pesquisa, pois demanda equipamentos e materiais comuns, como: cones Imhoff, centrífuga, balança analítica, mufla, pissetas, pipetas, entre outros.

O presente texto complementa o referido trabalho, apresentando um método para se determinar a distribuição granulométrica da areia presente no esgoto sanitário, com base no emprego da técnica de análise de imagem. Os autores deste trabalho acreditam que a utilização conjunta dos dois métodos constitui poderosa ferramente para o estudo e aprimoramento das unidades de desarenação atualmente empregadas em estações de tratamento de esgoto, como demonstra Prado (2006). Não obstante, as metodologias ainda carecerem do aperfeiçoamento em decorrência de sua utilização sistemática.

\section{Material e métodos}

\section{A análise de imagens}

Segundo Allen (1997), a análise de imagens é um ramo da estereologia, isto é, avaliação quantitativa ou qualitativa de feições geométricas tridimensionais expostas em imagens bidimensionais. Essa citação remete o leitor ao conceito de diâmetro equivalente, pois quando a análise de imagem é utilizada na determinação do tamanho de uma partícula, alguma característica geométrica de sua feição bidimensional (e.g. área projetada) é relacionada a uma única dimensão linear: o diâmetro equivalente.

Existem, basicamente, duas formas de se usar a análise de imagens para contagem e determinação de tamanho de partículas: manualmente ou usando sistemas de análise de imagens. Contar ou determinar tamanho de partículas "manualmente", por meio de análise de imagens, consiste em comparar partículas com retículos previamente calibrados via microscópio, sendo, por conseguinte, considerado o método absoluto de determinação de tamanho de partículas, pois se trata da única técnica pela qual se observam e se medem partículas individualmente. No entanto, essa característica torna sua utilização tediosa e extremamente lenta, logo, seu emprego deve restringir-se a avaliações qualitativas e a análises preliminares de amostras (ALLEN, 1997). Os sistemas de análise de imagens, mormente empregados em análises quantitativas de distribuição de tamanho de partículas (DTP), são usualmente compostos por seis etapas: i) aquisição das imagens; ii) detecção das feições de interesse; iii) processamento das imagens binárias; iv) calibração do equipamento; v) análise e realização das medidas e vi) tratamento dos dados e apresentação dos resultados.

No presente trabalho, foi empregado um sistema de análise de imagens para determinar a DTP da areia presente no esgoto sanitário afluente à ETE Jardim das Flores, município de Rio Claro (SP).

As etapas que compõem o sistema utilizado serão sucintamente descritas e comentadas neste texto, porquanto a pormenorização de todos os aspectos envolvidos na determinação de tamanho de partículas por meio de técnicas de análise de imagens fogem do escopo deste trabalho. Sugere-se, àqueles que desejarem mais informações sobre o tema, a leitura de textos especializados, como Russ (1991; 1994) e Gonzales e Woods (1993).

\section{Materiais e equipamentos empregados}

Para determinar a DTP da areia presente no esgoto sanitário bruto utilizando-se a técnica de análise de imagem, foram empregados os seguintes materias e equipamentos:

- Placa de vidro $(30$ x $25 \mathrm{~cm})$;

- Lamínulas;

- Fita adesiva transparente; 
- Microscópio óptico Olympus BX41 com ampliações de 4; 10; 20; 40 e 100 vezes;

- Câmera CCD (Coupled Charged Device) Samsung SDC 313 com dispositivo para acoplamento em microscópio óptico e saída para computador;

- Microcomputador;

- Fio de referência com diâmetro conhecido, para a calibração do software $(100 \mu \mathrm{m})$.

\section{Amostragem dos grãos de areia e aquisição das imagens digitais}

A amostragem e a aquisição das imagens, sem dúvida, são os pontos-chave da utilização da técnica de análise de imagens para a determinação da DTP. Deve-se garantir a contagem do maior número possível de partículas, pois uma das maiores críticas acerca da utilização da técnica recai sobre a representatividade estatística de seus resultados. Segundo Allen (1997), devem ser contadas, no mínimo, 625 partículas para que o erro amostral não ultrapasse $2 \%$.

As imagens empregadas no presente estudo foram obtidas de amostras de areia seca, as quais haviam sido extraídas de amostras de esgoto sanitário bruto por meio da metodologia proposta por Prado e Campos (2008) para determinar a concentração de areia presente em águas residuárias. Desta forma, pode-se afirmar que a técnica apresentada neste texto complementa a metodologia anteriormente referenciada.

As amostras de areia seca foram uma a uma espalhadas em placa plana de vidro posicionada sobre fundo branco de forma a garantir o contraste necessário para visualização dos grãos de areia (Figura 1). Após serem separados uns dos outros por meio de delicada agitação da placa de vidro, os grãos de areia foram amostrados utilizando-se um pedaço de fita adesiva transparente, não maior que a largura das lamínulas de vidro disponíveis.

A amostragem foi realizada cuidadosamente, para evitar a formação de aglomerados de grãos de areia, os quais dificultam a utilização de softwares de análise de imagens e impõem a necessidade da utilização de ferramentas de processamento e tratamento de imagem, as quais, em suma, alteram a imagem original, aumentando os erros inerentes à aplicação da técnica.

Para a aquisição das imagens, foram adotados os seguintes procedimentos:

- posicionar a lamínula no microscópio, acertar a iluminação e o foco, observando a imagem na tela do computador que deve estar conectado à câmera CCD acoplada ao microscópio;

- posicionar o fio de referência sobre a lamínula (obs.: caso o foco não seja alterado, a utilização do fio de referência em todas as fotos não será necessária; porém, a cada reajuste no foco, o fio de referência deve ser posicionado sobre a lamínula antes de a foto seguinte ser capturada);
- seguir um padrão pré-determinado de movimentação da lamínula ao tirar as fotos, para evitar que uma mesma partícula seja fotografada mais de uma vez. O padrão de movimentação utilizado nessa pesquisa é mostrado na Figura 2.

Foram utilizadas 15 amostras de areia seca. Para cada amostra, foram preparadas, em média, dez lamínulas; para cada lamínula, foram obtidas cerca de 18 imagens. Desta forma, pode-se concluir que o número total de imagens analisadas aproxima-se de 2.700, nas quais foram contados exatamente 22.531 grãos de areia, em média oito grãos por foto.

\section{Tratamento e processamento das imagens}

Os procedimentos envolvidos no tratamento e processamento das imagens (como, por exemplo, detecção das feições de interesse, processamento das imagens binárias, calibração do equipamento, análise

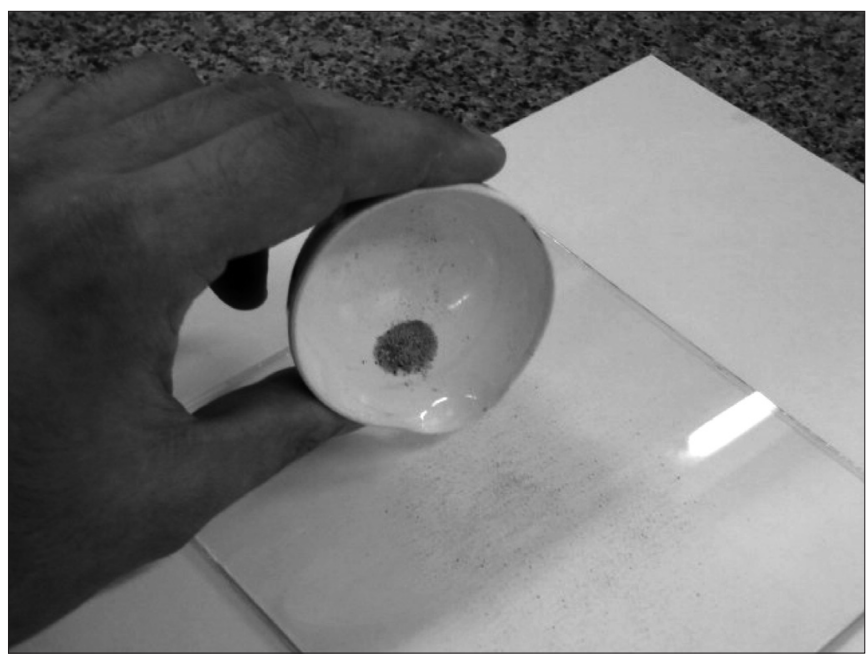

Figura 1 - Foto de uma amostra de areia seca sendo espalhada sobre a placa plana de vidro, posicionada sobre um fundo branco

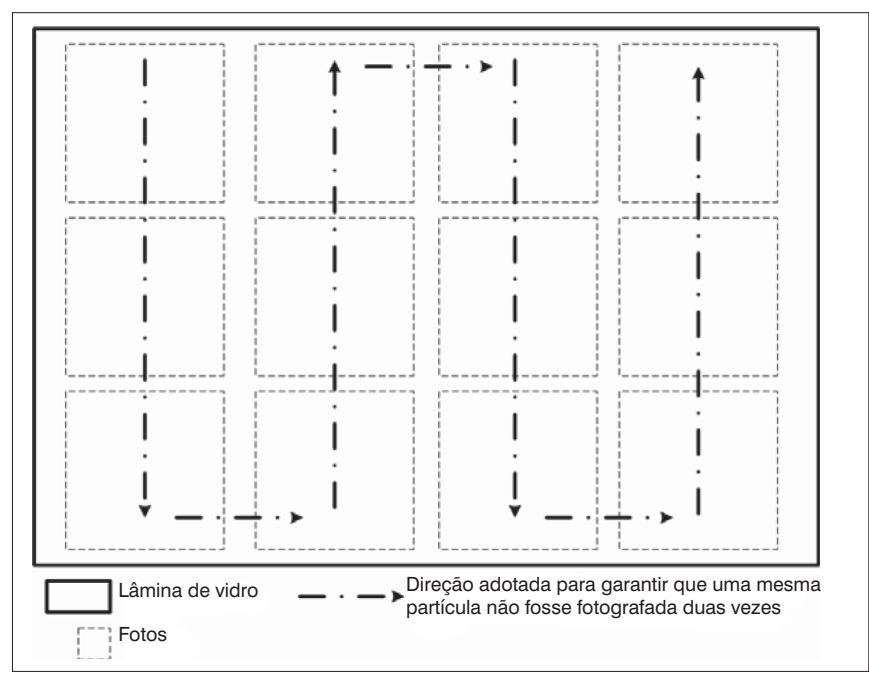

Figura 2 - Desenho esquemático do padrão de movimentação adotado ao se tirarem fotos de uma lâmina. 
e realização das medidas) foram realizados em um software aberto chamado Image-Tool versão 3.0. Este programa de análise de imagens, desenvolvido pelo Health Science Center da University of Texas de San Antonio, EUA, opera normalmente em plataforma Windows e pode ser baixado pela internet. Nas próximas seções, serão descritos somente os procedimentos que foram utilizados no processamento e análise das imagens digitais, pois independem do software empregado. Detalhes de como realizar tais procedimentos usando o ImageTool 3.0 podem ser obtidos no manual do usuário que acompanha o programa, ou ainda em Moruzzi (2005) e Moruzzi e Reali (2007).

\section{Detecção das feições de interesse ou detecção das bordas e segmentação dos objetos}

Toda imagem digital é formada por um número finito de elementos primários chamados pixels. Dependendo da profundidade do pixel, cada um desses elementos primários que compõem imagens digitais pode assumir grande quantidade de intensidades (tonalidades - níveis de brilho), que variaram de 16 tons (imagens de 4 bits por pixel) até 16.777.216 tons (imagens de 24 bits por pixel). As bordas de um objeto em uma imagem digital são regiões onde ocorrem mudanças de intensidade em certo espaço e direção; portanto, quanto maior a diferença de intensidade entre um objeto e o plano de fundo (background) de uma imagem, mais nítidas serão as bordas desse objeto.

Os procedimentos adotados na detecção das feições de interesse têm como única finalidade tornar eminente a diferença de intensidade entre os pixels que compõem o objeto e aqueles que compõem o plano de fundo, evidenciando-se, assim, as bordas dos objetos que se pretende analisar.

O primeiro procedimento a ser realizado é a conversão das imagens coloridas originais em imagens em escala de cinzas. Com isso, as imagens originais que possuíam 16.777.216 níveis de brilho ( 24 bits Figura 3A) são transformadas em imagens com 256 níveis de brilho (8 bits Figura 3B).

A etapa seguinte, segmentação dos objetos de interesse, é a etapa mais delicada da análise de imagens, pois todas as medidas que se pretende realizar baseiam-se nas dimensões das regiões por ela identificadas. Com esta etapa, procura-se distinguir os objetos uns dos outros e do plano de fundo, permitindo, assim, que o programa interprete pixels contíguos e os agrupe em regiões. O procedimento utilizado para a segmentação foi a limiarização, que é a utilização da intensidade dos pixels para distingui-los. Para tanto, as imagens foram binarizadas, isto é, transformadas em imagens de 1 bit, as quais possuem apenas duas intensidades diferentes, como mostra a Figura 3C.

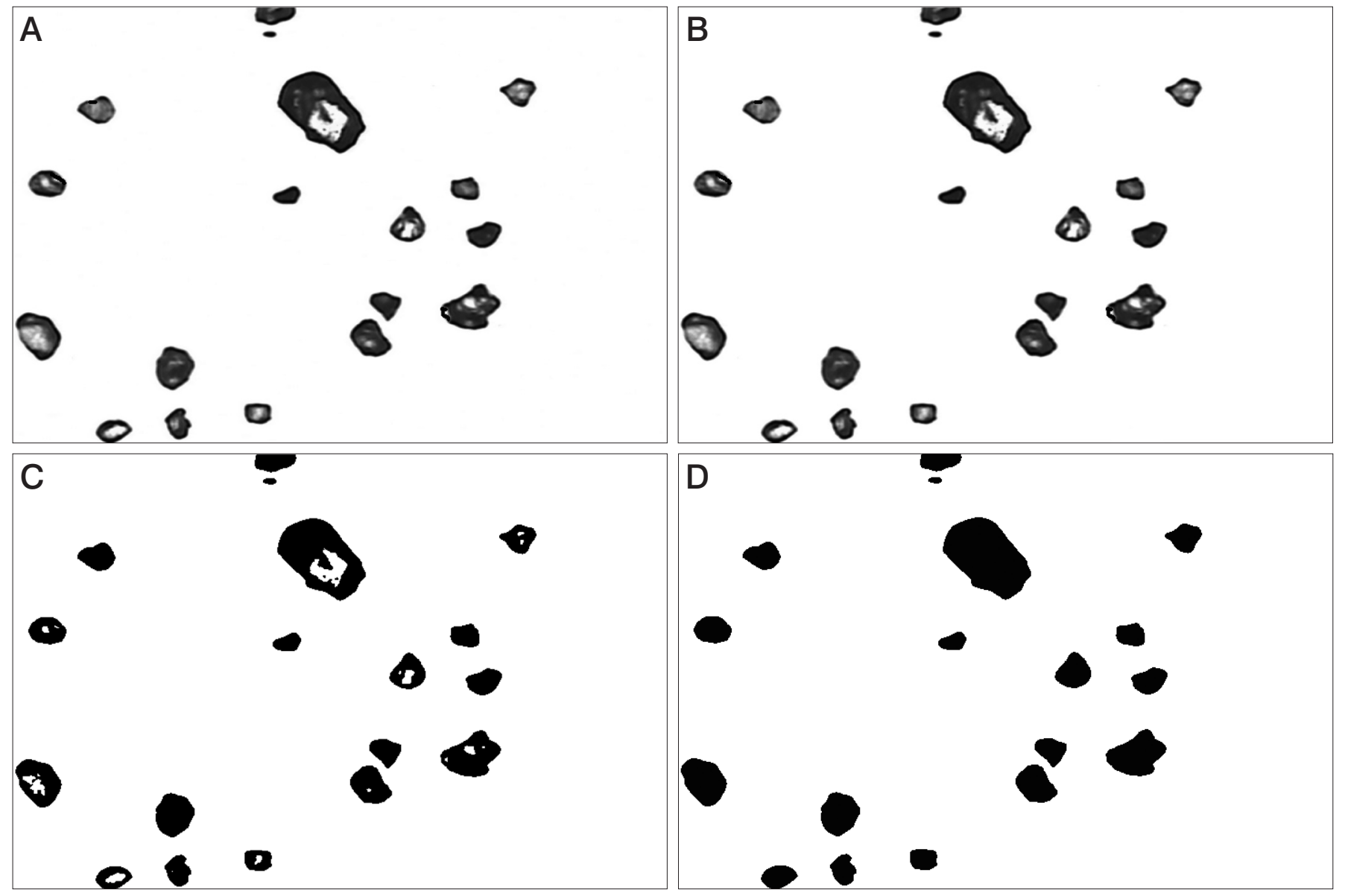

Figura 3 - Conversão das imagens coloridas originais (16.777.216 níveis de brilho), em imagens em escala de cinzas (256 níveis de brilho), em imagem binarizada ( 1 bit - 2 níveis de brilho) e imagem binarizada processada, respectivamente. 


\section{Processamento das imagens binárias}

Os grãos de areia geralmente são partículas translúcidas, o que faz com que suas imagens binarizadas, dependendo da posição da fonte de luz, apresentem espaços em branco, como mostra a Figura 3C. Imagens como essa não são adequadas para a realização das medições, pois tais "buracos" devem ser preenchidos para que o programa interprete a região como um único objeto (Figura 3D).

Outro problema muito comum é a presença de aglomerados de partículas nas fotos, chamados clusters. Esses aglomerados devem ter suas partículas separadas para que o programa não o reconheça como um único objeto. Antes de as medições de tamanho serem conduzidas, essas e outras inadequações das imagens binarizadas devem ser contornadas com o emprego de ferramentas de processamento de imagens binárias chamadas operações morfológicas. Entre elas podem-se destacar:

- erosion (erosão): a última camada de pixels do contorno dos objetos é removida, diminuindo suas áreas. Essa operação morfológica é utilizada para separar objetos que se tocam e para eliminar objetos muito pequenos;

- dilation (dilatação): adiciona-se uma camada de pixels ao contorno dos objetos, aumentando suas áreas. Essa operação morfológica é utilizada para preencher pequenos "buracos" e para fechar objetos côncavos;

- fill holes (preenchimento de buracos): são adicionados pixels a "buracos" localizados dentro de regiões fechadas. Essa operação morfológica é utilizada para preencher "buracos";

- watershed (separação de águas): por meio de operações matemáticas, denominadas 'transformadas de distâncias', objetos que se sobrepõem ou se tocam são separados.

As duas primeiras operações, dentro do possível, devem ser usadas de forma combinada, ou seja, ciclos de "n" erosões seguidos de ciclos de "n" dilatações, ou vice-versa. Vale destacar que as operações morfológicas descritas, de alguma forma alteram a imagem binária original, causando inevitável perda de informação; para corroborar tal afirmativa, pode-se recorrer a uma perspicaz citação de Allen (1997):

O objetivo de todo processamento e tratamento de imagens é melhorar a imagem original, no entanto a única coisa certa é o fato de que a imagem original é alterada. (p. 132).

Portanto, as operações morfológicas devem ser usadas com critério, pois podem provocar sérias distorções nos resultados finais de DTP obtidos pela técnica.

\section{Calibração do programa}

Todo programa de análise de imagens necessita de uma imagem de calibração para que possam ser conduzidas medidas de tamanho.
Isso porque se deve "informar" ao programa qual é a escala da imagem, ou seja, atribuir a um pixel uma unidade de comprimento. Para isso, deve-se obter uma imagem de referência com algum objeto de tamanho previamente conhecido. Neste trabalho, foi utilizado um fio de platina de diâmetro de $100 \mu \mathrm{m}$; este fio era posicionado sobre a lamínula e, então, fotografado. Não é necessário usar o objeto de referência em todas as fotos, porém, sempre que o foco da imagem for reajustado, uma nova imagem de calibração deve ser obtida, pois o aumento ou diminuição da distância focal altera o tamanho dos objetos na imagem.

\section{Análise e medições}

Uma vez concluído o processo de segmentação e tratamento das imagens binárias, podem ser realizadas as medidas sobre a imagem. Essas medidas podem ser agrupadas em duas classes: medidas de campo, referentes ao campo visual como um todo (por exemplo, número de objetos, área total dos objetos etc.); e medidas de região, referentes aos objetos individualmente (como tamanho, diâmetro equivalente, perímetro dos objetos, área projetada, fatores de forma, entre outras). Essa etapa não requer interferência humana, pois é toda realizada pelo programa, ficando a cargo do experimentador somente a escolha de quais medidas devem ser realizadas. Neste trabalho, serão apresentados resultados de número e tamanho dos objetos, os quais receberam tratamento estatístico em planilha eletrônica (Microsoft Excel).

\section{Resultados e discussão}

\section{Distribuição granulométrica da areia no esgoto sanitário}

Os resultados obtidos pela aplicação da técnica de análise de imagens empregada neste trabalho são distribuições de número de partículas por faixas de tamanho, em outras palavras, distribuições numéricas de partículas, dados de difícil interpretação. Por essa razão, as distribuições numéricas foram transformadas em distribuições volumétricas de tamanho de partícula que, em suma, correspondem a distribuições mássicas de tamanho de partícula, quando apresentadas em termos percentuais. Vale ressaltar que tal artifício matemático, apesar de se tratar de aproximação, constitui excelente ferramenta para análise da distribuição da massa de areia presente no esgoto sanitário e, consequentemente, da eficiência de remoção de unidades de desarenação.

As Figuras 4 e 5 apresentam, respectivamente, histogramas e curvas de frequências relativas numéricas e volumétricas dos dados coletados na análise de imagem realizada em 15 amostras (22.531 partículas) de areia seca, as quais foram extraídas do esgoto sanitário afluente da ETE Jardim das Flores, município de Rio Claro (SP). 


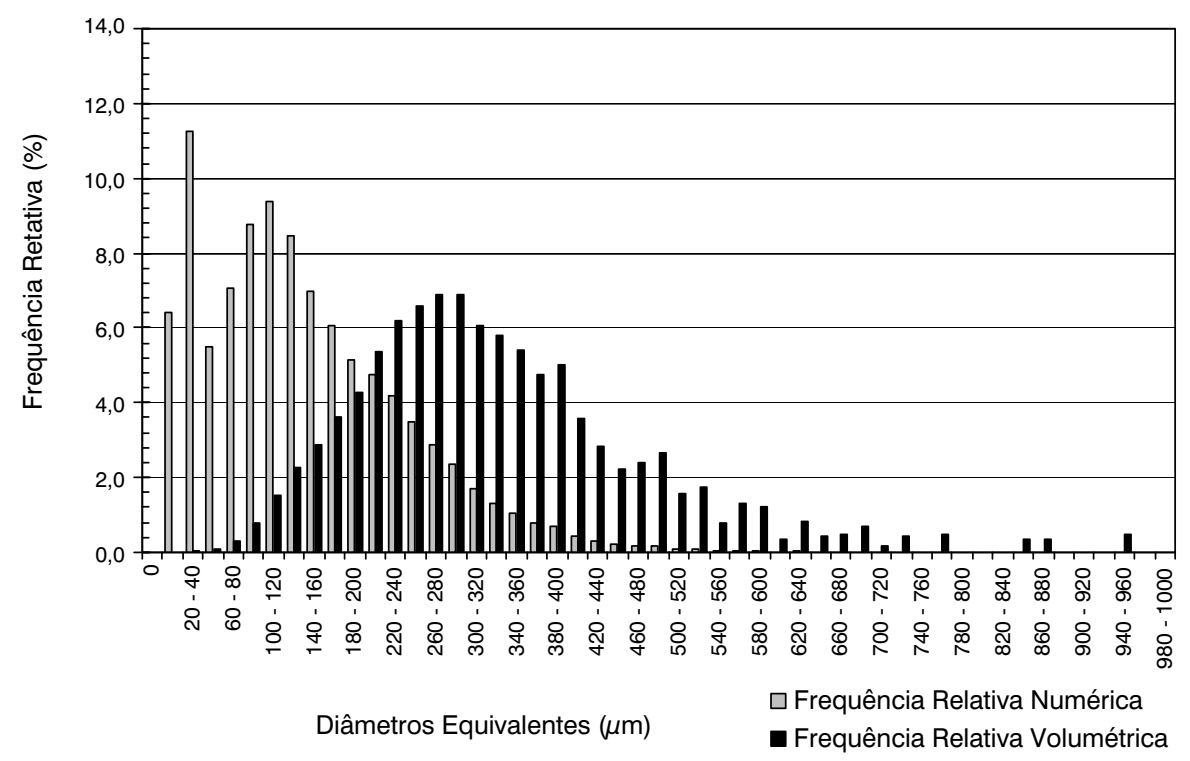

Figura 4 - Histograma das distribuições de frequências relativas numéricas e volumétricas obtidas a partir de 22.531 partículas observadas no conjunto de dados composto pelas 15 amostras estudadas

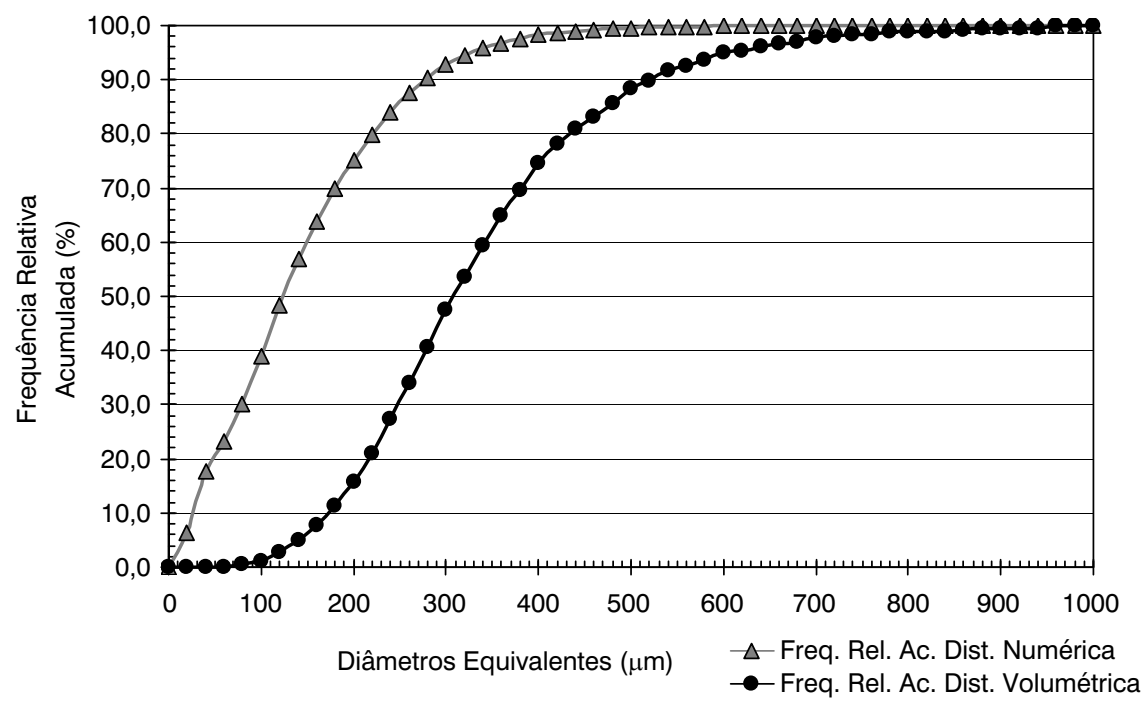

Figura 5 - Gráfico das distribuições de frequências relativas acumuladas numéricas e volumétricas obtidas a partir de 22.531 partículas observadas no conjunto de dados composto pelas 15 amostras estudadas.

Pode-se observar que os histogramas mostrados na Figura 4 apresentam formatos diferentes, pois a faixa de tamanho que concentra o maior número de partículas difere daquela que concentra a maior massa (ou volume) de partículas. Os intervalos que apresentam maior quantidade de partículas são: de $20 \mu \mathrm{m}$ a $40 \mu \mathrm{m}$ (aproximadamente $11 \%$ do número total de partículas) e de $100 \mu \mathrm{m}$ a $120 \mu \mathrm{m}$ (aproximadamente 9\% do número total de partículas). Entretanto, o intervalo que concentra maior massa de partículas está entre 260 $\mu \mathrm{m}$ e $300 \mu \mathrm{m}$, com aproximadamente 14\% da massa total de areia presente no esgoto.
Na Figura 5, pode-se observar grande distanciamento entre as curvas de distribuição de frequências relativas acumuladas em termos numéricos e volumétricos. Observa-se também que, em média, menos de $2 \%$ da massa total de areia presente no esgoto sanitário estudado é composta por partículas menores ou iguais a 100 $\mu \mathrm{m}$; todavia, em termos numéricos, essas partículas correspondem a 39\% do total. Já as partículas menores ou iguais a $200 \mu \mathrm{m}$ respondem em média por $16 \%$ da massa de areia presente no esgoto sanitário; consequentemente, eficiências de remoção de areia superiores a $84 \%$ não devem ser esperadas se o esgoto afluente de uma 
unidade de desarenação possuir grãos de areia com distribuição granulométrica semelhante à apresentada na Figura 5. Em termos numéricos, as partículas menores ou iguais a $200 \mu \mathrm{m}$ correspondem a $75 \%$ do total.

Outra forma de apresentação de resultados obtidos pela análise de imagem são os diâmetros estatísticos, os quais podem ser entendidos como medidas de tendências centrais das distribuições de tamanho de partículas por eles representados. A Tabela 1 mostra quatro medidas da DTP da areia encontrada no esgoto sanitário afluente da ETE Jardim das Flores. As Equações 1 e 2 foram empregadas para o cálculo de dois diâmetros estatísticos distintos: diâmetro de Saulter e o Aritmético.

Saulter $[3,2]=\frac{\sum d_{A p}^{3}}{\sum d_{A p}^{2}}$

Equação 1

Aritmético $[1, \mathrm{~N}]=\frac{\sum d_{A p}}{N}$

Equação 2

Em que:

$\mathrm{d}_{\mathrm{Ap}}$ : diâmetro da esfera equivalente de mesma área projetada obtido da análise de imagens (L);

$\mathrm{N}$ : número de partículas contadas;

Saulter [3,2]: diâmetro estatístico que relaciona volume e área (L);

Aritmético $[1 ; \mathrm{N}]$ : média aritmética dos diâmetros obtidos pela análise de imagem (L).

Os diâmetros: máximo e mínimo, encontrados nas amostras, demonstram o espalhamento da distribuição. Percebe-se que o esgoto sanitário estudado carreia largas faixas de tamanho de grãos de areia, desde diminutas partículas de pouco mais de 4,0 $\mu \mathrm{m}$ até grãos de areia de aproximadamente $1,0 \mathrm{~mm}(1.000 \mu \mathrm{m})$. Observa-se que o diâmetro aritmético $(142 \mu \mathrm{m})$ está próximo às faixas de tamanho que apresentam o maior número de partículas (Figura 4), enquanto o diâmetro de Saulter (indicado para estudos em que partículas interagem com meios fluídos) pertence à faixa de tamanho na qual se concentra o maior volume e, consequentemente, a maior massa de partículas (Figura 4). Por conseguinte, esse diâmetro estatístico poderia tornarse um importante parâmetro de verificação da eficiência de um desarenador. Unidades capazes de reduzir o diâmetro de Saulter dos grãos de areia carreados pelos seus afluentes a valores inferiores a $150 \mu \mathrm{m}$ ou $200 \mu \mathrm{m}$ poderiam ser consideradas desarenadores eficientes, pois removeriam a maior parte das partículas que ocasionam problemas aos demais equipamentos e unidades de uma ETE.

\section{Avaliação crítica acerca do emprego da análise de imagens}

O emprego de técnicas de análise de imagem para determinar a distribuição granulométrica dos grãos de areia presentes no esgoto sanitário vem ao encontro das recomendações propostas por Santos et al (2004) para a escolha da técnica de determinação de tamanho de partículas que deve ser empregada em um determinado estudo. No referido trabalho, os autores destacam a importância de se avaliarem: i) a natureza da amostra (seca, dissolvida, ou em suspensão; solubilidade das partículas; tamanho as partículas, etc.); ii) a tradição da utilização do método; iii) o custo de aquisição, manutenção e operação do equipamento; iv) a disponibilidade de mão-de-obra especializada; v) tempo de resposta; e vi) a facilidade de obtenção, tratamento e interpretação dos dados.

Ainda hoje, não se pode afirmar que exista uma técnica de determinação de tamanho de partícula tradicionalmente empregada na área de saneamento, todavia podem-se destacar três técnicas como as mais usadas em pesquisa: as técnicas de varredura de fluxo (contadores de partículas - Contadores Coulter e Contadores ópticos); as técnicas de varredura de campo (granulômetros à luz laser - LALLS, ou Low Angle Light Laser Scattering) e as técnicas de peneiramento.

Os contadores Coulter e ópticos têm sua utilização limitada à contagem de partículas finas $(0,5 \mu \mathrm{m}$ a $500 \mu \mathrm{m})$, distribuídas em faixas de tamanho estreitas, pois foram desenvolvidos para a contagem de glóbulos brancos e vermelhos do sangue (ALLEN, 1997). Na área de tratamento de efluentes líquidos, esses equipamentos têm sido utilizados para estudo de unidades de tratamento de água, como filtros rápidos, flotadores etc., uma vez que, as faixas de tamanho de partícula, mormente observadas nos afluentes e efluentes dessas unidades, permitem sua utilização (LEWIS; HARGESHEIMER; YENTSCH, 1992; O'SHAUGHNESSY et al, 1997; GELDER; CHOWDHURY; LAWLER, 1999).

Biggs et al (2005) reportam a experiência bem sucedida do uso de granulômetro a laser no estudo da DTP de sedimentos provenientes de sistemas de coleta de esgoto do tipo combinado. Nesse trabalho, os autores usaram, com sucesso, um granulômetro a laser para estudos em escala piloto do comportamento de sedimentos acumulados em sistemas combinados de coleta de esgoto das cidades de Loenen (Holanda) e Dundee (Inglaterra). Não obstante o sucesso alcançado na referida pesquisa, o alto custo de aquisição e manutenção desses equipamentos e a necessidade de mão-de-obra altamente especializada dificultam o emprego dessa técnica para a determinação da distribuição granulométrica da areia presente no esgoto. Outro ponto importante refere-se ao "tamanho" da amostra necessária para realização das medições, pois, durante o desenvolvimento da presente

Tabela 1 - Diâmetros estatísticos obtidos a partir das 22.531 partículas observadas no conjunto composto pelas 15 amostras estudadas.

Diâmetros estatísticos $(\mu \mathrm{m})$

\begin{tabular}{lc} 
Saulter [3,2] & 273 \\
\hline Aritmético [1,N] & 142 \\
\hline Mínimo & 4,5 \\
\hline Máximo & 942 \\
\hline № de Partículas Contadas & 22.531
\end{tabular}


pesquisa, os autores deste trabalho não obtiveram sucesso ao empregar um granulômetro a laser para determinar a DTP das pequenas quantidades de areia encontradas em amostras de esgoto bruto de aproximadamente um litro.

O peneiramento, técnica tradicionalmente utilizada para determinar distribuição granulométrica de amostras de areia, certamente é uma opção viável para se determinar a DTP da areia presente no esgoto sanitário como mostram Moilleron, Perez e Garnaud (2005). No referido trabalho, os autores empregaram o peneiramento para fracionar, em diferentes faixas de tamanho de partículas, amostras de sedimentos de diversos desarenadores da cidade de Paris (França) e, então, estudaram a distribuição de contaminantes, como metais pesados, hidrocarbonetos e matéria orgânica, em cada uma das faixas de tamanho. Todavia, o emprego do peneiramento requer amostras de areia seca de pelo menos $150 \mathrm{~g}$, valor elevadíssimo em comparação à quantidade de areia normalmente carreada pelo esgoto sanitário. Segundo Prado e Campos (2008), o esgoto sanitário afluente da ETE Jardim das Flores apresenta concentrações médias de areia entre $20 \mathrm{mg} / \mathrm{L}$ a $73 \mathrm{mg} / \mathrm{L}$, deste modo seria necessária a coleta de amostras com aproximadamente $7,5 \mathrm{~m}^{3}$ de esgoto bruto para se garantir a extração de massa suficiente de areia seca para a realização de ensaios de peneiramento.

Constata-se, pelo exposto nos parágrafos anteriores, que nenhuma das técnicas de determinação de tamanho de partículas "tradicionalmente" empregadas em estudos na área de tratamento de água e esgoto adequa-se à determinação de distribuições granulométricas da areia encontrada em pequenas amostras de esgoto sanitário. Não obstante, como mostram os resultados expendidos no presente texto, a técnica de análise de imagens descrita demonstrou-se bastante viável, porquanto não existem restrições à sua utilização para se determinarem distribuições granulométricas de pequenas amostras de areia seca com largas faixas de tamanho de partículas. Além disso, os resultados obtidos de sua aplicação apresentam satisfatória representatividade, pois uma grande quantidade de partículas foi analisada (ALLEN, 1997).

Apesar de ser viável e fornecer resultados de excelente qualidade, a técnica de análse de imagens apresentada neste texto, certamente, não é a resposta a todas as questões relacionadas à determinação da distribuição granulométrica da areia presente no esgoto sanitário, pois apresenta os mesmos inconvenientes relacionados à utilização de técnicas de determinação de tamanho de partículas que envolvem análise de imagem, isto é, o elevado tempo necessário para obtenção dos resultados.

$\mathrm{Na}$ presente pesquisa, foram analisadas aproximadamente 2.700 imagens, considerando que o processamento e tratamento de cada imagem requerem, em média, 5 minutos, pode-se inferir que foram necessários cerca de 28 dias ( 8 horas de trabalho diário) para obtenção dos dados brutos, os quais foram posteriormente submetidos a tratamento estatístico em planilha eletrônica. Isso ocorre porque todas as imagens devem ser individualmente tratadas, uma vez que a determinação do limiar de binarização e o emprego das operações morfológicas são etapas visuais que dependem da tomada de decisão do experimentador.

Seguramente, este trabalho não esgota o tema, pois a aplicação de técnicas de determinação de tamanho de partículas em pesquisas na área de tratamento de efluentes líquidos é assunto relativamente recente, complexo e com muitas peculiaridades, porém extremamente promissor. A técnica descrita neste texto, apesar de apresentar dificuldades no que se refere ao elevado tempo de resposta e ao quase artesanal processo de amostragem dos grãos de areia, demonstra grande aplicabilidade no estudo e aprimoramento de desarenadores que, apesar de serem considerados de vital importância para o bom funcionamento de equipamentos e unidades de operação e processo que os sucedem, carecem até mesmo de metodologia padronizada para determinação de suas eficiências.

\section{Conclusões}

Os resultados e discussões apresentados neste texto permitem concluir que a técnica de determinação de tamanho de partículas por análise de imagens descrita, embora bastante laboriosa e demorada, mostrou-se uma poderosa ferramenta para o estudo da distribuição granulométrica da areia presente no esgoto sanitário. Consequentemente, sua utilização e aprimoramento poderão contribuir para o desenvolvimento de unidades de desarenação que, apesar de serem reconhecidamente importantes para o correto funcionamento de diversos sistemas de saneamento, encontram-se, atualmente, à margem do desenvolvimento tecnológico experimentado pela área de tratamento de efluentes líquidos nas últimas décadas.

\section{Agradecimentos}

Os autores deste trabalho agradecem à Coordenação de Aperfeiçoamento de Pessoal de Nível Superior (CAPES) pela bolsa de doutorado concedida, à Prominas do Brasil pelo financiamento da pesquisa, ao Departamento de Águas e Energia Elétrica (DAEE) do município de Rio Claro por permitir a realização da pesquisa nas dependências da ETE Jardim das Flores, e aos técnicos do LATAR do Departamento de Hidráulica e Saneamento da Escola de Engenharia de São Carlos que colaboraram em todas as etapas do trabalho de pesquisa. 


\section{Referências}

ALLEN, T. Particle size measurement. 5. ed. London: Chapman \& Hall, 1997. Powder sampling and particle size measurement, v. 1

BIGGS, C.A. et al. Investigating the effect of storm events on the particle size distribution in a combined sewer simulator. Water Science and Technology, v. 52, n. 3, p. 129-136, 2005.

CAMP, T.R. Grit chamber design. Sewage Work Journal, v. 14, n. 2, p. 368-381, Mar. 1942.

GARDNER, P.; DEAMER, A. An evaluation of methods for assessing the removal efficiency of a grit separation device. Water Science and Technology, v. 33, n. 9, p. 269-275, 1996.

GELDER, A.M.V.; CHOWDHURY, Z.K.; LAWLER, D. Conscientious particle counting. Journal of American Water Works Association, v. 91, n. 12, p. 64-76, Dec. 1999.

GIERGER, H. Snadfange fur Abwasserklanranlagen. Archivfur Wasserwirtschaft des Reichsuerbandes des Deutschen Wasserwirtschaft E.V., Arbeitskreis, Wasserwirtschaft. In: NSBDT, n. 58, 1942. (Translated to English for the American Public Works Association by Patricia Ure Petersen)

GONZALES, R.C.; WOODS, R. Digital image processing. Addison Wesley, 1993

LEWIS, C.M.; HARGESHEIMER, E.E.; YENTSCH, C.M. Selecting particle counters for process monitoring. Journal of American Water Works Association, v. 84, n.12, p.46-53, dec. 1992.

MOILLERON, R.; PEREZ, J.; GARNAUD, S. Grain size distribution of metals and polycyclic aromatic hydrocarbons in silt trap sediments from the combined sewer network of Paris (France). Water Science and Technology, v. 52, n. 3, p. 111-118, 2005.

MORUZZI, R.B. Avaliação da influência da distribuição de tamanho de partículas e do binômio velocidade/tempo de detenção na zona de reação no desempenho da flotação com utilização de sonda ultrasônica e técnica de análise por imagem. 240 f. Tese (Doutorado) - Escola de Engenharia de São Carlos, Universidade de São Paulo, São Carlos, 2005.

MORUZZI, R.B.; REALI, M.A.P. Método para determinação de distribuição de tamanho de microbolhas (DTMB) em sistemas de flotação (FAD) para tratamento de águas utilizando a análise de imagem digital. Revista Engenharia Sanitária e Ambiental, Rio de Janeiro, v. 12, n. 3, p. 273-283, jul./set. 2007.

O'SHAUGHNESSY,P.T. et al. Evaluating particle counters Journal of American Water Works Association, v. 89, n.12, p. 64-76, dec. 1997.

PRADO, G.S. Concepção e estudo de uma unidade compacta para tratamento preliminar de esgoto sanitário composta por separador hidrodinâmico por vórtice e grade fina de fluxo tangencial. 240 f. Tese (Doutorado) - Escola de Engenharia de São Carlos, Universidade de São Paulo, São Carlos, 2006.

PRADO, G.S.; CAMPOS, J.R. Determinação da quantidade de areia no esgoto sanitário: metodologia e estudo de caso. Revista Engenharia Ambiental e Sanitária, Rio de Janeiro, v. 13, n. 3, p. 306-312, jul-set. 2008.

RUSS, J.C. The image processing handbook. 2. ed. CRC Press Inc. 1994.

Computer-assisted microscopy: the measurement and analysis of images. New York: Plenum Press \& sons, 1991.

SANTOS, H.R. et al. Aplicabilidade das técnicas de determinação de tamanho de partículas em sistemas de tratamento de água e esgoto. Revista Engenharia Sanitária e Ambiental, Rio de Janeiro, v. 9, n. 4, p. 291-300, out./dez. 2004.

WILSON, G.E. Is there grit in your sludge? Civil Engineering Magazine, v. 55, n. 4, p. 61-63, Apr. 1985. 